\title{
Relationship between food portion size and dietary energy density in Irish children
}

\author{
E. O’Donovan, J. Walton and A. Flynn \\ School of Food and Nutritional Sciences, University College Cork, Cork, Republic of Ireland
}

It is now widely accepted that both food portion sizes and dietary energy density (ED) may influence energy intake. However, data are sparse on the relationship of food portion size and dietary ED in free-living populations. The aim of this research was to investigate the association of the portion size of certain foods with dietary ED in free-living Irish children using data from the National Children's Food Survey (http://www.iuna.net). A 7-d weighed food record was used to collect food intake data from 594 children (293 boys, 301 girls). Analysis of dietary intake data was carried out using WISPC (Tinuviel Software, Anglesey, UK) which contains McCance and Widdowson's The Composition of Foods, 6th edition ${ }^{(1)}$. Food portion size (g), defined as the weight of the food consumed per eating occasion was estimated for each day the food was consumed. When a food was consumed on more than one occasion the largest portion size was assigned. Dietary ED ( $\mathrm{kcal} / \mathrm{g}$ ) was calculated for each day using food only, excluding beverages. Data were split by the quintile of food portion size and the mean dietary ED was examined across the fifths.

\begin{tabular}{|c|c|c|c|c|c|c|c|c|}
\hline \multirow[t]{2}{*}{ Food group } & \multirow[t]{2}{*}{$\begin{array}{l}\text { Number } \\
\text { of days }\end{array}$} & \multicolumn{5}{|c|}{ Dietary energy density (ED) (mean) } & \multirow[t]{2}{*}{$P$} & \multirow[t]{2}{*}{$\begin{array}{l}\text { Food portion size }(\mathrm{g}) \\
\text { (interquintile median) } \\
\text { Q1, Q2, Q3, Q4, Q5 }\end{array}$} \\
\hline & & Q1 & Q2 & Q3 & Q4 & Q5 & & \\
\hline Biscuits & 2307 & 1.93 & 1.99 & 2.04 & 2.11 & 2.14 & $<0.001$ & $13,20,25,31,47$ \\
\hline Cakes & 754 & 1.99 & 2.05 & 2.05 & 2.08 & 2.26 & $<0.001$ & $22,31,44,61,92$ \\
\hline Chocolate confectionery & 1618 & 1.95 & 2.04 & 2.15 & 2.18 & 2.3 & $<0.001$ & $15,22,29,40,58$ \\
\hline Non-chocolate confectionery & 1135 & 2.01 & 2.01 & 2.12 & 2.13 & 2.28 & $<0.001$ & $8,18,25,37,60$ \\
\hline Carbonated beverages & 1333 & 2.05 & 2.07 & 2.2 & 2.17 & 2.29 & $<0.001$ & $146,200,250,330,500$ \\
\hline Savoury snacks & 1608 & 2.00 & 2.08 & 2.11 & 2.15 & 2.3 & $<0.001$ & $15,20,25,30,40$ \\
\hline Ready to eat breakfast cereals & 2803 & 2.01 & 2.01 & 1.98 & 2.03 & 2.13 & $<0.001$ & $18,28,38,46,67$ \\
\hline Cheese & 1048 & 1.95 & 1.96 & 1.97 & 1.99 & 2.15 & $<0.001$ & $11,18,21,30,44$ \\
\hline Total fruit & 1887 & 1.98 & 1.86 & 1.78 & 1.7 & 1.63 & $<0.001$ & $50,90,113,134,178$ \\
\hline Vegetables & 1509 & 1.99 & 1.87 & 1.76 & 1.73 & 1.6 & $<0.001$ & $16,34,50,71,108$ \\
\hline Bread & 3359 & 1.95 & 2.01 & 2.03 & 2.01 & 2.04 & $<0.01$ & $32,50,66,75,99$ \\
\hline Potatoes & 1513 & 1.91 & 1.87 & 1.79 & 1.69 & 1.63 & $<0.001$ & $53,97,130,180,250$ \\
\hline Chipped potatoes & 1366 & 2.17 & 2.16 & 2.21 & 2.2 & 2.17 & NS & $48,78,100,132,203$ \\
\hline
\end{tabular}

Dietary ED was positively associated with portion size intake for a number of food groups, with the highest increases (10-15\% for Q5 v. Q1) seen for biscuits, cakes, confectionery (chocolate and non-chocolate), carbonated beverages and savoury snacks. Negative associations of dietary ED were observed for portion size intakes of potatoes, vegetables and fruit with a reduction (Q1 $v$. Q5) of 15-20\%. As dietary ED has been associated with energy intake and obesity, these results may be useful in establishing food-based dietary guidelines in relation to food portion size.

The project was funded by the Irish Government under the National Development Plan 2000-2006.

1. Food Standards Agency (2002) McCance and Widdowson's The Composition of Foods, 6th ed. Cambridge: Royal Society of Chemistry. 